\title{
Immunochemical investigation of the interaction of egg- yolk lipoproteins with bovine spermatozoa
}

\author{
A. D. Cookson, A. N. Thomas and J. A. Foulkes \\ MAFF, Cattle Breeding Centre, Shinfield, Reading RG2 9BZ, U.K.
}

\begin{abstract}
Summary. Antiserum was raised in rabbits against an egg-yolk lipoprotein fraction previously shown to have cryoprotective properties. It was used in conjunction with alkaline phosphatase-conjugated goat anti-rabbit $\mathrm{IgG}$ to demonstrate lipoprotein interaction with bovine spermatozoa. The lipoprotein bound firmly to spermatozoa and was not removed by extensive washing, suggesting that the lipoprotein had become irreversibly associated with the sperm membranes.
\end{abstract}

\section{Introduction}

Egg yolk is widely used and generally accepted as an essential ingredient in diluents employed for the freezing of bovine spermatozoa for use in artificial insemination (AI). Although the efficacy of egg yolk in conferring protection to spermatozoa during cooling to temperatures above freezing was first described nearly 50 years ago (Phillips, 1939), attempts to characterize the component responsible for and the mechanism of cryoprotection have not been conclusive. Phospholipids (Kampschmidt, Mayer \& Herman, 1953), phosphatidylcholine (Martin, 1963; Lanz, Pickett \& Komarek, 1965; Masuda \& Nishikawa, 1972), various lipid extracts and lipoprotein fractions (Bialy, Ludwick, Hess \& Ely, 1957; Gebauer, Pickett, Komarek \& Gaunya, 1970) and specific lipoproteins (Masuda \& Nishikawa, 1972; Foulkes, 1977) have all been reported to confer cryoprotection during cooling, freezing and thawing, as assessed by maintenance of cellular integrity and retention of motility after thawing. Foulkes \& Stewart (1977) have demonstrated the maintenance of fertility in spermatozoa frozen in an egg-yolk lipoprotein diluent prepared from egg-yolk lipoprotein fraction 3 (Foulkes, 1977) and used for AI. Foulkes (1977) and MacDonald \& Foulkes (1981) have suggested that egg-yolk lipoproteins may exert their cryoprotective effect by interacting with and stabilizing the sperm membrane. Foulkes (1977) has proposed that egg-yolk components bind firmly to bovine sperm membranes.

Enzyme-labelled antibody methods have proved useful tools for the detection of antigens in solution (Engvall \& Perlmann, 1971) and in tissue (Nakane \& Pierce, 1966). These techniques provide a method for the detection of molecules to which a specific antibody can be raised. This paper describes the use of an enzyme-labelled antibody method to investigate the interaction of egg-yolk lipoprotein fraction 3 with bovine spermatozoa.

\section{Materials and Methods}

Preparation of egg-yolk lipoproteins. Egg-yolk lipoproteins were prepart 1 by density flotation and gel filtration according to the method of Foulkes (1977). Three fractions were collected, one from 
the first major peak (Fraction 1) and two incompletely resolved fractions from the second peak (Fractions 2 and 3). The fractions were concentrated, using an Amicon TCF-2 concentration cell, to a final concentration of $10 \mathrm{mg}$ protein $/ \mathrm{ml}$ as determined by the method of Lowry, Rosebrough, Farr \& Randall (1951).

Antiserum production. Egg-yolk lipoprotein Fraction 3 was exhaustively dialysed against phosphate-buffered saline (PBS; $0.1 \mathrm{M}, \mathrm{pH} \mathrm{7.0)}$ and diluted to $1 \mathrm{mg}$ protein/ml before innoculation into rabbits. Rabbits were injected subcutaneously with $0.5 \mathrm{mg}$ protein in $50 \%$ Freund's Complete Adjuvant (FCA) into several sites dorsally. After 4 weeks these animals received a further $0.25 \mathrm{mg}$ protein in $50 \%$ FCA by the same route. Blood was collected from the ear vein 10 days later and the serum was separated by centrifugation. Antiserum from 3 rabbits was pooled after assessment of specificity by the double-immunodiffusion test (Ouchterlony \& Nilsson, 1973). The pooled antiserum reacted specifically with Fractions 2 and 3 . There was no cross-reaction with Fraction 1.

Semen collection. Semen was obtained from fertile Friesian bulls by using an artificial vagina. Semen of high sperm density and motility was pooled and maintained at $30^{\circ} \mathrm{C}$. Sperm density was assessed by turbidity using a digital photometer (IMV, L'Aigle, France) before diluting the semen to the appropriate sperm concentration.

Lipoprotein coating of cuvettes. Polystyrene cuvettes (LKB: $50 \mathrm{~mm} \times 10 \mathrm{~mm}$ ) were coated with lipoprotein Fraction $3(1 \mathrm{ml} ; 2.5 \mu \mathrm{g}$ protein $/ \mathrm{ml})$ at $37^{\circ} \mathrm{C}$ in sodium carbonate/bicarbonate buffer $(0.1 \mathrm{M} ; \mathrm{pH} \mathrm{9.6)}$ for $30 \mathrm{~min}$ before washing 3 times ( $2 \mathrm{ml} / \mathrm{wash}$ ) with PBS containing Tween 20 $(0.05 \%)$.

Assay. Semen was diluted in the diluent being investigated and dispensed into polystyrene tubes ( $75 \mathrm{~mm} \times 10 \mathrm{~mm} ; 1 \mathrm{ml} /$ tube). Spermatozoa were allowed to equilibrate $\left(4^{\circ} \mathrm{C} ; 16 \mathrm{~h}\right)$ before centrifugation $(320 \mathrm{~g} ; 5 \mathrm{~min})$. The supernatant was discarded and the pellet resuspended in trisodium citrate $(3 \% \mathrm{w} / \mathrm{v} ; \mathrm{pH} 7.0 ; 3 \mathrm{ml})$ to disperse egg-yolk granules before centrifugation $(320 \mathrm{~g} ; 5 \mathrm{~min})$. The washing procedure was repeated a further 5 times using PBS ( $3 \mathrm{ml} / \mathrm{wash})$. After the final wash, the supernatant was discarded and the pellet resuspended in PBS $(0.3 \mathrm{ml})$.

The rabbit antiserum to lipoprotein Fraction 3 was diluted (1/4000) in $0.25 \%$ bovine serum albumin (BSA) in PBS to reduce non-specific reactions and $1 \mathrm{ml}$ was added to the tube. Tubes were vortexed $(5 \mathrm{sec})$ and incubated $\left(30 \mathrm{~min}, 37^{\circ} \mathrm{C}\right)$. After incubation tubes were centrifuged $(1300 \mathrm{~g} ; 10$ $\mathrm{min})$ and the supernatant $(1 \mathrm{ml})$ was recovered and transferred into polystyrene cuvettes previously coated with Fraction 3 . The recovered supernatant was incubated in the cuvettes $\left(30 \mathrm{~min} ; 37^{\circ} \mathrm{C}\right)$ before washing with PBS/Tween 20 ( 3 washes; $2 \mathrm{ml} /$ wash). Diluted IgG-fraction goat anti-rabbit IgG/alkaline phosphatase conjugate (Miles Biochemicals, Slough, U.K.) was added (1 ml; 1/1500; diluted in $0.25 \% \mathrm{BSA}$ in PBS) and the cuvettes were incubated at $37^{\circ} \mathrm{C}$ for $30 \mathrm{~min}$ before washing 3 times with PBS/Tween 20 ( $2 \mathrm{ml} /$ wash). The cuvettes were emptied and drained over absorbent paper for 2 min before substrate ("Sigma 104" phosphatase substrate, $1.4 \mathrm{mg} / \mathrm{ml}$; Sigma Chemical Co., Poole, U.K.) in diethanolamine buffer $\left(10 \% \mathrm{v} / \mathrm{v}, \mathrm{pH} 9 \cdot 8\right.$, containing $\left.0.01 \% \mathrm{w} / \mathrm{v} \mathrm{MgCl}_{2} .6 \mathrm{H}_{2} \mathrm{O}\right)$ was added $(1 \mathrm{ml})$. The reaction was stopped after $40 \mathrm{~min}$ by the addition of $\mathrm{NaOH}(0 \cdot 2 \mathrm{M} ; 2 \mathrm{ml})$. Six controls were included in each assay, i.e. anti-lipoprotein IgG only (Control A), untreated spermatozoa (Control B), uncoated cuvettes (Control C), no antiserum (Control D), no conjugate (Control E) and substrate only (Control S).

Absorbance was determined on a Cecil CE-292 spectrophotometer at $405 \mathrm{~nm}$ using Control S as blank. The degree of alkaline phosphatase conjugate bound to the cuvette was proportional to the amount of anti-lipoprotein IgG recovered. The percentage of anti-lipoprotein IgG recovered was calculated using Control $\mathrm{A}$ as $100 \%$. Final results were expressed as percentage of anti-lipoprotein IgG bound to the spermatozoa (100 - IgG recovered). The proportion of anti-lipoprotein IgG bound to spermatozoa provided a measure of the lipoprotein bound to spermatozoa. 


\section{Experimental Details and Results}

Binding of egg-yolk lipoprotein to spermatozoa

Semen was diluted and equilibrated at sperm concentrations ranging from 0 to $1 \times 10^{8}$ spermatozoa/ml in an egg-yolk diluent $(20 \% \mathrm{v} / \mathrm{v}$ egg yolk; $11 \% \mathrm{w} / \mathrm{v}$ lactose; $4.7 \% \mathrm{v} / \mathrm{v}$ glycerol) or yolk-free diluent $(11 \% \mathrm{w} / \mathrm{v}$ lactose; $4.7 \% \mathrm{v} / \mathrm{v}$ glycerol $)$. After equilibration, spermatozoa were washed once with $3 \%(\mathrm{w} / \mathrm{v})$ trisodium citrate $2 \mathrm{H}_{2} \mathrm{O}(\mathrm{pH} 7 \cdot 0)$ and 5 times with PBS.

The binding of anti-lipoprotein IgG to spermatozoa previously equilibrated with egg yolk was significantly greater than that to unequilibrated spermatozoa (Text-fig. 1). The total binding increased with sperm number while the non-specific binding of IgG to untreated spermatozoa, although tending to increase with sperm number, remained relatively low.

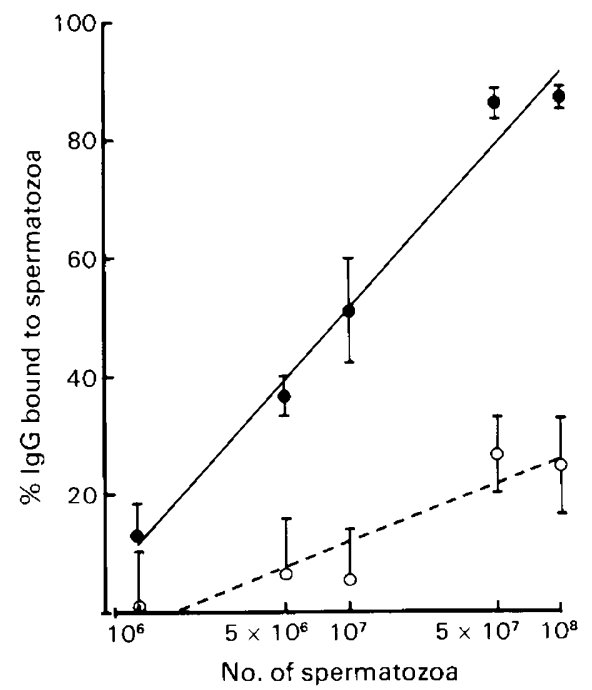

Text-fig. 1. Percentage of anti-lipoprotein $\mathrm{IgG}$ binding to egg yolk-treated $(\mathcal{O})$ and untreated $(O)$ bovine spermatozoa. Values are means \pm 2 s.e. for 6 determinations.

\section{Resistance of sperm-lipoprotein binding to washing}

Semen was diluted and equilibrated at $1 \times 10^{8}$ spermatozoa $/ \mathrm{ml}$ in egg-yolk diluent $(20 \% \mathrm{v} / \mathrm{v}$ egg yolk; $11 \% \mathrm{w} / \mathrm{v}$ lactose $; 4.7 \% \mathrm{v} / \mathrm{v}$ glycerol $)$. After equilibration $\left(4^{\circ} \mathrm{C}, 16 \mathrm{~h}\right)$ spermatozoa were washed once with $3 \%(\mathrm{w} / \mathrm{v})$ trisodium citrate $2 \mathrm{H}_{2} \mathrm{O}(\mathrm{pH} 7.0)$ and up to 11 times with PBS. After each wash spermatozoa were examined for anti-lipoprotein IgG binding. It was also possible to measure the relative quantity of egg-yolk lipoprotein in the wash supernatants by using a modification of the indirect binding assay whereby wash supernatant $(0.3 \mathrm{ml})$ was incubated $(30 \mathrm{~min})$ with anti-lipoprotein antiserum $(1 \mathrm{ml})$ before transferring the mixture $(1 \mathrm{ml})$ into cuvettes coated with Fraction 3 . Free lipoprotein in the supernatant bound with anti-lipoprotein $\mathrm{IgG}$, thus reducing its binding to the lipoprotein-coated cuvettes.

The binding of anti-lipoprotein IgG to the spermatozoa remained high $(88 \cdot 5-94 \cdot 5 \%$ of the maximum) through 10 wash cycles (Text-fig. 2), whereas IgG binding to free lipoprotein in the wash supernatant decreased to and remained at relatively low levels $(10 \cdot 5-21 \cdot 5 \%)$ after 6 washes. A reduction in binding to spermatozoa (to $77 \%$ ) together with a concomitant increase in binding (to $29.5 \%$ ) to free lipoprotein in the supernatant was evident after washes 11 and 12 when sperm fragments were microscopically visible in the wash supernatants. 


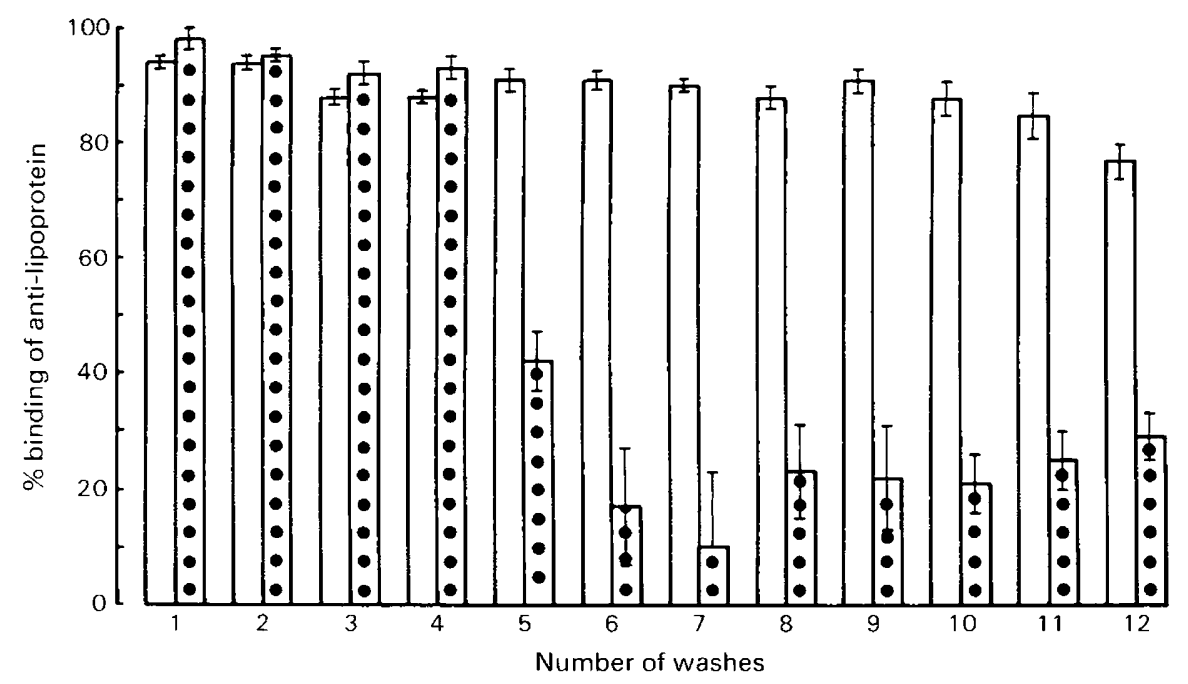

Text-fig. 2. Binding of anti-lipoprotein IgG to sperm-bound ( $\square$ ) or supernatant ( $\square$ ) lipoprotein after washing. Values are means \pm 2 s.e. for 4 determinations.

\section{Effect of whole egg yolk or lipoprotein fractions upon total lipoprotein binding to spermatozoa}

Pooled spermatozoa were divided and equilibrated $\left(4^{\circ} \mathrm{C}, 16 \mathrm{~h}\right)$ at $1 \times 10^{8}$ spermatozoa $/ \mathrm{ml}$ in 3 diluents with various concentrations of egg yolk or egg-yolk lipoprotein : (a) egg yolk in PBS (0-20\% $\mathrm{v} / \mathrm{v}$ egg yolk), (b) Fraction 3 in PBS (0-10 $\mathrm{mg}$ protein/ml), (c) Fractions $2+3$ in PBS (0-10 mg protein $/ \mathrm{ml}$ ). Lipoprotein protein concentrations in diluents (b) and (c) corresponded to their concentrations in the whole egg-yolk diluents.
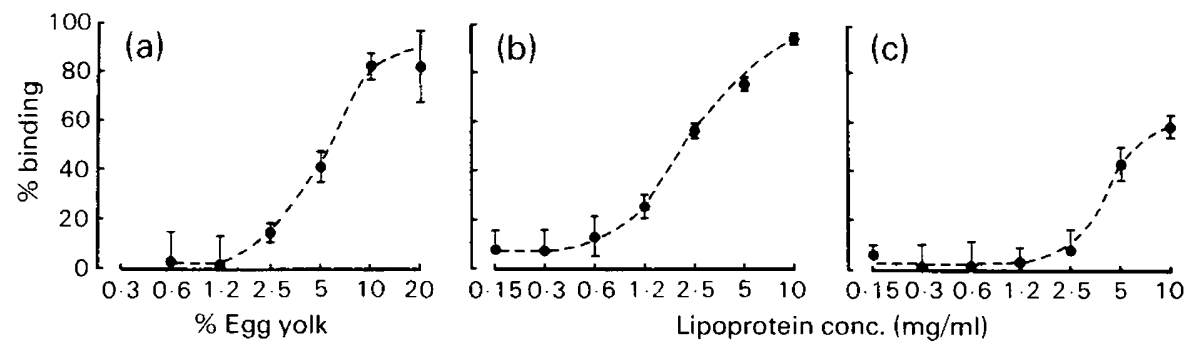

Text-fig. 3. Binding of anti-lipoprotein IgG to bovine spermatozoa incubated in diluents with (a) egg yolk, (b) lipoprotein Fraction 3 or (c) lipoprotein Fractions $2+3$. Values are means \pm 2 s.e. for 4 determinations.

The binding of anti-lipoprotein IgG to spermatozoa previously equilibrated in egg yolk or Fraction 3 diluent was not significantly different $(P>0.05)$ (Text-figs $3 \mathrm{a} \& \mathrm{~b}$ ). Binding of anti-lipoprotein IgG to spermatozoa equilibrated in the diluent prepared from Fractions $2+3$ (Text-fig. 3c) was significantly lower than in whole egg yolk or Fraction 3 diluents $(P<0.05)$.

\section{Discussion}

The results obtained using the indirect lipoprotein binding assay strongly support the contention that certain lipoproteins bind firmly to bovine spermatozoa. The total binding of egg-yolk lipo- 
protein to spermatozoa increased with sperm number (Text-fig. 1), suggesting consistent levels of binding of lipoproteins to individual spermatozoa. The degree of binding was not reduced by extensive washing of the spermatozoa (Text-fig. 2), supporting earlier work in which no reduction in the binding of radiolabelled egg yolk components to bovine spermatozoa occurred after washing 20 times (Foulkes, 1977). Similarly, MacDonald \& Foulkes (1981) could detect no reduction in the fluorescence associated with lipoprotein binding to bovine spermatozoa after extensive washing. The reduction in binding detected after washing 11 and 12 times in this study was probably due to cell loss: sperm fragments were microscopically visible in the supernatants from these washes. Washing 10 times may be the practical limit using this washing procedure before significant cell disruption occurs. Conversely, Watson (1975) concluded that egg-yolk components form a reversible attachment to ram spermatozoa and could be removed by washing in a yolk-free diluent. This could suggest that species differences exist in the interaction of egg-yolk components with spermatozoa and may reflect the difficulty encountered when attempting to freeze ram spermatozoa. Using a modified and more practical method, Watson (1979) suggested a more permanent binding of lipoprotein to ram spermatozoa.

The immunochemical techniques used in this study have allowed the interaction of a specific lipoprotein fraction with bovine spermatozoa to be studied. The antiserum produced in rabbits reacted specifically with egg-yolk lipoproteins which eluted as the second major peak after column chromatography on Sepharose S-2B, i.e. Fractions 2 and 3. No cross-reaction existed between the antiserum and lipoprotein Fraction 1. Electrofocussing studies could not resolve more than one protein band from Fractions 2 and 3 and immunoelectrophoresis studies revealed only one precipitin band between the anti-lipoprotein antiserum and Fractions 2 and 3 (unpublished results). No qualitative differences in the lipid contents of the three lipoprotein fractions were found in earlier studies (Foulkes, 1977). It is reasonable to assume, however, that while Fractions 2 and 3 differ quantitatively in their lipid content they share a similar protein, whereas Fraction 1 contains a protein serologically distinct from that in Fractions 2 and 3.

The binding of lipoprotein to spermatozoa exposed to whole egg yolk was at a level indistinguishable from the binding achieved using lipoprotein Fraction 3 alone at levels corresponding to its abundance in whole egg yolk (Text-figs $3 \mathrm{a} \& \mathrm{~b}$ ). This would suggest that lipoprotein Fraction 3 is the major component in egg yolk which has affinity for sperm membranes. This was further supported by the reduced binding which occurred when the whole of the second lipoprotein peak (i.e. Fractions $2+3$ ) was used at the same total protein concentration (Text-fig. $3 \mathrm{c})$. If Fractions 2 and 3 share the same common protein with identical antibody affinity, this might suggest that the lipid content of the lipoprotein determines its ability to bind to sperm membranes either directly via the lipid residues or by optimal presentation of the protein or entire lipoprotein molecule. This suggestion supports that of Watson (1981) who concluded that the lipid content of lipoproteins was important in determining both their ability to bind to spermatozoa and their degree of cryoprotection.

Liproprotein Fraction 3 (Foulkes, 1977) and the apparently similar "peak 2" (Pace \& Graham, 1974) have previously been shown to be effective in protecting bull semen during cooling, freezing and thawing. Earlier work (Foulkes, 1977; Watson, 1979; MacDonald \& Foulkes, 1981) based on radioactive labelling of egg-yolk lipids or 1-anilino-naphthalene-8-sulphonate fluorescence has suggested interactions between egg-yolk components and spermatozoa although these techniques were unable to demonstrate the binding of specific egg-yolk components because of lack of specificity in the labelling techniques. The present study, however, demonstrates by specific antibody labelling using a novel enzyme-labelled technique selective binding of a particular eggyolk lipoprotein (Fraction 3 ) to bovine spermatozoa. The results show that this lipoprotein, which is known to possess cryoprotective properties (Foulkes \& Stewart, 1977), is the major egg-yolk component that binds to bovine sperm membranes. This strengthens the theory that the cryoprotective action of egg yolk involves the stabilization of the sperm membranes through the binding of certain egg-yolk lipoproteins. 
We thank Mr D. A. Wassall of the Central Veterinary Laboratory, Weybridge, Surrey, for the electrofocussing data.

\section{References}

Bialy, G., Ludwick, T.M., Hess, E.A. \& Ely, F. (1957) Influence of lipoprotein on the freezing of bovine spermatozoa. J. Dairy Sci. 40, 1189-1192.

Engvall, E. \& Perlmann, P. (1971) Enzyme-linked immunosorbent assay (ELISA). Quantative assay of immunoglobulin G. Immunochemistry 8, 871-873.

Foulkes, J.A. (1977) The separation of lipoproteins from egg yolk and their effect on freezing of bovine spermatozoa. J. Reprod. Fert. 49, 277-284.

Foulkes, J.A. \& Stewart, D.L. (1977) Fertility of dairy cattle after artificial insemination with semen frozen in a lipoprotein diluent. J. Reprod. Fert. 51, 175-177.

Gebauer, M.R., Pickett, B.W., Komarek, R.J. \& Gaunya, W.S. (1970) Motility of bovine spermatozoa extended in "defined" diluents. J. Dairy Sci. 53, 817-823.

Kampschmidt, R.F., Mayer, D.T. \& Herman, H.A. (1953) Lipid and lipoprotein constituents of egg yolk in the resistance and storage of bull spermatozoa. J. Dairy Sci. 36, 733-742.

Lanz, R.N., Pickett, B.W. \& Komarek, R.J. (1965) Effect of lipid additives on pre- and post-freeze survival of bovine spermatozoa. J. Dairy Sci. 48, 1692-1697.

Lowry, O.H., Rosebrough, N.J., Farr, A.L. \& Randall, R.J. (1951) Protein measurements with the Folin phenol reagent. J. biol. Chem. 193, 265-275.

MacDonald, B.J. \& Foulkes, J.A. (1981) A spectrofluorometric investigation, using 1-anilino-naphthalene-8sulphonate, of the interaction between washed bovine spermatozoa and seminal plasma or egg-yolk lipoprotein. J. Reprod. Fert. 63, 407-414.

Martin, I.C.A. (1963) Effects of lecithin, egg yolk, fructose and period of storage at $5^{\circ} \mathrm{C}$ on bull spermatozoa deep frozen to $-79^{\circ} \mathrm{C} . J$. Reprod. Fert. 6, 441-449.

Masuda, H. \& Nishikawa, Y. (1972) Studies on the substances in egg yolk affecting the viability and metabolism of spermatozoa. III. Substances in the non-dialyzable portion of egg yolk promoting the survival of spermatozoa of goats, bulls and horses. Jap. J. zootech. Sci. 43, 355-359.

Nakane, P.K. \& Pierce, G.B. (1966) Enzyme labelled antibodies, preparation and application. J. Histochem. Cytochem. 14, 929-931.

Ouchterlony, O. \& Nilsson, L.A. (1973) Immunodiffusion and immunoelectrophoresis. In Handbook of Experimental Immunology, pp. 19.1-44. Ed. D. M. Weir. Blackwell Scientific Publications, Oxford.

Pace, M.M. \& Graham, E.F. (1974) Components in egg yolk which protect bovine spermatozoa during freezing. J. Anim. Sci. 39, 1144-1149.

Phillips, P.H. (1939) Preservation of bull semen. J. biol. Chem. 130, 415, abstr.

Watson, P.F. (1975) The interaction of egg yolk and ram spermatozoa studied with a fluorescent probe. $J$. Reprod. Fert. 42, 105-111.

Watson, P.F. (1979) An objective method for measuring fluorescence of individual sperm cells labelled with 1anilino naphthalene-8-sulphonate (ANS) by means of photomicrography and densitometry. J. Microsc. $117,425-429$.

Watson, P.F. (1981) The roles of lipid and protein in the protection of ram spermatozoa at $5^{\circ} \mathrm{C}$ by egg yolk lipoprotein. J. Reprod. Fert. 62, 483-492.

Received 19 July 1983 